\title{
Robustness of Building Design Integrating Phase Change Materials in Nordic and Mediterranean Climates
}

\author{
Juan Manuel Cruz ${ }^{1}$, Francesco Goia ${ }^{1}$, Albert Castell ${ }^{2}$ \\ ${ }^{1}$ Norwegian University of Science and Technology, NTNU, Trondheim, Norway \\ ${ }^{2}$ Escola Politècnica Superior, Universitat de Lleida, Lleida, Spain
}

\begin{abstract}
The aim of the research presented in this paper is to evaluate, through a simulation study, the "robustness", of the use of Phase Change Materials (PCMs) in the building construction, when boundary conditions that differ from the ones used in the design/planning phase appear.

The methodology is based on the extensive use of the simulation environment EnergyPlus, applied to a case study building (a small-medium office building), located in two different climates (a Nordic climate and a Mediterranean climate), and through a comparative analysis (one case with PCM incorporated in the envelope and indoor partitions, and one reference case without integrated PCM). Different boundary conditions are parametrically studied, and the impact of these variations on the total energy use (for heating and cooling) of the building assessed.

The results show that the use of PCM leads to a more stable energy use than the reference case (i.e. the deviation from the estimated energy use in case of no variation of the boundary conditions), in almost all the cases, and regardless of the climate. This technology can therefore represent a "safe" and "robust" solution in terms of expected performance, even if its behaviour is not always characterised by linear behaviours.
\end{abstract}

\section{Introduction}

The use of Phase Change Materials (PCMs) has been since long proposed as an effective solution to contribute to the lowering of the energy use for heating and cooling of buildings Kośny, J. (2015). These materials, usually integrated in opaque building envelope components, partition walls, or ceilings (Pomianowski et al. 2013), or even in transparent systems (Vigna et al. 2018), are characterised by high thermal energy storage potentials, and can therefore contribute to increase the thermal inertia of the building. An increase of the thermal capacity of the construction is often considered a suitable strategy for Zero Emission Buildings (ZEBs) to lower the energy use for building air conditioning by reducing the fluctuation in the indoor air temperature.

Compared to more traditional ways to increase the thermal capacity of the building (i.e. to increase the mass of conventional building materials), the use of PCMs may, in theory, lead to counterproductive effects. This potential risk is due to the non-linear behaviour of a
PCM, since its thermal storage capability changes drastically between the phase change range and the solid/liquid phase. Because of this feature, the performance of these systems might be more difficult to predict than that of more conventional systems.

The design process of buildings integrating PCM requires the optimisation of the PCM layer (quantity, position, and PCM's thermorphysical properties) under the assumptions of a series of boundary conditions. These boundary conditions concern the outdoor climate, other building components, the user occupancy, the operation of the building, and many more. However, once the building is built, many of these boundary conditions may differ from those considered in the design phase to optimise and select the PCM layer. Such a difference between adopted boundary conditions and realistic/actual boundary conditions under operation may lead to a different performance of the building, and the question whether PCM-based solutions are more or less robust to these unpredicted changes is still open.

This paper aims therefore at deepening the understanding of the deviation between the expected and the actual performance of a building equipped with PCM-based elements. The goal is to assess whether the use of PCM-based system may or may not represent a drawback in terms of "robustness" of the predicted building performance.

\section{Methods}

The research method used in this activity is based on numerical modelling and simulation of PCM through a whole-building energy simulation tool, EnergyPlus (Castell et al. 2018), and the use of one case-study building to exemplify the behaviour of systems with and without PCM-based components.

\section{Case-study building and building envelope systems}

The case-study building is designed to reach an extremely high-energy (heating and cooling) performance. Because of the conceptual/theoretical nature of this study, such a performance (which is as low as $2-3 \mathrm{kWh} / \mathrm{m}^{2}$ for heating and $2-3 \mathrm{kWh} / \mathrm{m}^{2}$ for cooling) is achieved by combining a set of active and passive systems that might not be, all in all, cost-effective. However, the aim of the case study was to stretch the border of what is possible to achieve in order to see the extreme consequences in the use of PCMs. 


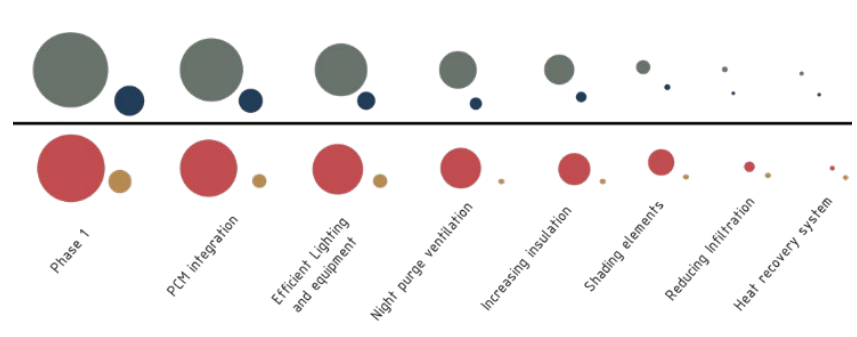

Figure 1: Integrated Energy Design process
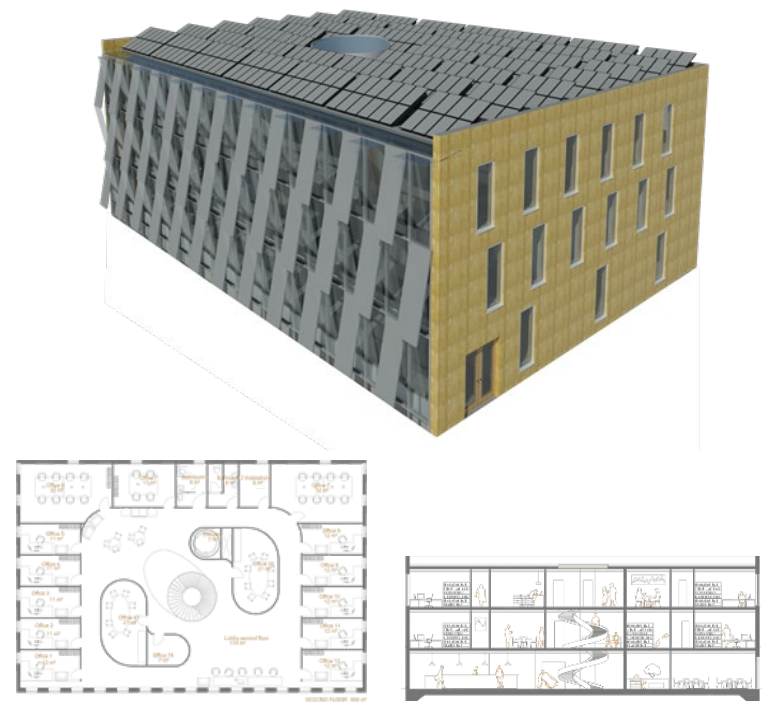

Figure 2: 3D, floor plan, and vertical section of the case-study building.

The remarkably low energy demand has been achieved through an iterative optimisation process and fine-tuning of all the different aspects of the building, combining different integrated energy design measures, from passive to active strategies (figure 1), leading, in theory, to lower the heating energy use. From ca. $45 \mathrm{kWh} / \mathrm{m}^{2}$ (in Trondheim) and ca. $8 \mathrm{kWh} / \mathrm{m}^{2}$ (in Barcelona) to ca. $3 \mathrm{kWh} / \mathrm{m}^{2}$, and the cooling energy use from ca. $20 \mathrm{kWh} / \mathrm{m}^{2}$ (in Trondheim) and ca. $50 \mathrm{kWh} / \mathrm{m}^{2}$ (in Barcelona) to less than $1 \mathrm{kWh} / \mathrm{m}^{2}$.

These values correspond to the thermal energy to be delivered to (heating) or subtracted from (cooling) the thermal zones, and do not include neither any energy use for auxiliaries, nor any inefficiency in the distribution, regulation, and control of the HVAC plant.

The case-study building is a hypothetical reference building designed for a small-medium office (3-storey height, nearly $10 \mathrm{~m}$ tall), with a total net area of approximately $1500 \mathrm{~m}^{2}$ (Figure 2). The building is rectangular (floor print: $18.2 \mathrm{~m} \times 27.5 \mathrm{~m}$ ) and compact, thus designed to reduce heat losses. It contains an open staircase placed in the centre of the floor (with a floor area of $25 \mathrm{~m}^{2}$ ) that provides circulation for the building, and acts as a chimney for enhancing natural ventilation (exhaust) as well as a light-well in the middle of the building.

All the facades have similar design but a different glazed surface: the north-facing facade has a window-to-wall ratio (WWR) of approximately $13 \%$, east- and west- a WWR just greater than $22 \%$, while the south-exposed facade has a WWR of $50 \%$ and integrated PV panels.

The building (both the reference case building and the one equipped with any PCM-enhanced building component) has a cross-laminated timber (CLT) structure and wooden-frame facades. The features of the building envelope components are reported in Table 1.

While the reference case building does not include any PCM-enhanced component, the case building with PCMenhanced building elements has a layer of (macro encapsulated) Rubitherm RT 25HC (paraffin-based PCM), with a thickness of $5 \mathrm{~mm}$, placed right behind the gypsum board layer. The selected PCM has a nominal transition temperature equal to $25{ }^{\circ} \mathrm{C}$ and a nominal latent heat of fusion of $210 \mathrm{~kJ} / \mathrm{kg}$ (Rubitherm, 2019).

All the exterior walls, indoor partitions, and ceiling surfaces are modelled with the PCM layer. The selection of the PCM layer, its thermophysical characteristics, and its position is the results of a preliminary optimisation analysis, where different alternatives (in terms of position and nominal transition temperature) are simulated, and the one leading to the lowest heating and cooling energy use was eventually selected.

After simulating different PCM melting temperatures (from 10 to $42^{\circ} \mathrm{C}$ ) both before and after the insulation layer, the results show how, both in Trondheim and in Barcelona, when the PCM is located in the interior side of the insulation layer, the heating and cooling loads were significantly lower than when located in the outer layer. In addition, when melting at $25^{\circ} \mathrm{C}$, the heating and cooling loads where lower than using other melting temperatures. The reason might be that the thick insulation, placed in the building envelope, acts as a barrier and the interior temperature does not vary that much when the PCM is placed after the insulation layer than when there is not PCM.

\section{Simulation environment, settings, and workflow}

The fictitious office building is modelled using Revit and is converted to EnergyPlus 8.9, leading to 44 thermal zones. The version adopted for this simulation study is the first one that allows the modelling of hysteresis effects in EnergyPlus. Due to the requirements set for the simulations of PCM layers, the embedded Conduction Finite Difference algorithm is selected, and the time step of the simulation set to $3 \mathrm{~min}$.

Heating and cooling energy use is calculated by using an Ideal Load Air System for each thermal zone. This modelling approach assures, in this study, that each zone of the building receives enough heating/cooling to maintain the indoor air within the desired value range. The indoor air control is based on a dual set point (lower limit equal to $20^{\circ} \mathrm{C}$ and upper limit equal to $26^{\circ} \mathrm{C}$ ). The ventilation plan of the building is simulated through the features integrated in the Ideal Load Air System, based on the recommended airflow rate (ISO 15251, 2012). A highly efficient $(88 \%)$ heat recovery system with economiser (and night cooling) is simulated. 


$\begin{array}{lcc}\text { Component } & \text { Nordic Climate } & \begin{array}{c}\text { Mediterranean } \\ \text { Climate }\end{array} \\ \text { Opaque wall } & U_{\text {wall }}=0.10 \mathrm{~W} / \mathrm{m}^{2} \mathrm{~K} & U_{\text {wall }}=0.14 \mathrm{~W} / \mathrm{m}^{2} \mathrm{~K} \\ \text { Floor } & U_{\text {floor }}=0.24 \mathrm{~W} / \mathrm{m}^{2} \mathrm{~K} & U_{\text {floor }}=0.24 \mathrm{~W} / \mathrm{m}^{2} \mathrm{~K} \\ \text { Roof } & U_{\text {roof }}=0.07 \mathrm{~W} / \mathrm{m}^{2} \mathrm{~K} & U_{\text {roof }}=0.07 \mathrm{~W} / \mathrm{m}^{2} \mathrm{~K} \\ \text { Window } & U_{\text {window }}=0.6 \mathrm{~W} / \mathrm{m}^{2} \mathrm{~K} & U_{\text {window }}=0.6 \mathrm{~W} / \mathrm{m}^{2} \mathrm{~K} \\ \text { Thermal bridge } & \text { Norm. coefficient }=0.023 \mathrm{~W} / \mathrm{m}^{2} \mathrm{~K} \\ \text { Air leakage } & 0.6 \mathrm{~m}^{3} /\left(\mathrm{m}^{3} \mathrm{~h}\right) @ 50 \mathrm{~Pa}\end{array}$

Table 1: Features of the building envelope components.

Internal loads (lighting, plugs, and occupancy) were set following best practice values (ASHRAE, 2017) and then parametrically changed in the robustness analysis. Simulations were run for the entire year, in both climates (see following paragraph), and for both the reference and PCM-enhanced building. To define the base-case scenarios (i.e. the case where the building is built and operated as it should be), simulations were run using the previously described settings. The heating and cooling energy use, expressed as $\mathrm{kWh} / \mathrm{m}^{2}$ is calculated and then used as key performance indicator to assess the robustness of the PCM-enhanced building.

\section{Climates and variable parameters}

To evaluate the performance in a cold-dominated (Nordic) climate, the fictitious building is located in Trondheim, Norway $\left(63^{\circ} 25^{\prime} \mathrm{N} ; 10^{\circ} 23^{\prime} \mathrm{E}\right)$. To evaluate the performance in a warm-dominated (Mediterranean) climate, the fictitious building is located in Barcelona, Spain $\left(41^{\circ} 23^{\prime} \mathrm{N} ; 2^{\circ} 11^{\prime} \mathrm{E}\right)$. Comparing PCMs in two different climatic contexts is relevant to see if this performs better in cold dominated climates or in warm dominated climates.

Annual simulations are run in both locations for the reference case scenario (all settings as planned) with and without PCM. Afterwards, a series of runs where one parameter at a time is changed is done. Four categories group the variables tested in the parametric analysis: i) internal gains; ii) external gains; iii) building material properties; and iv) PCM properties. For each category, three to four different parameters are tested (Figure 3).

The impact of internal gains has been tested through the parametric analysis of: the occupancy density (from 0.5 person per office to 2 persons per office); the lighting load (from no artificial lighting to incandescent bulbs); and the equipment load (with different levels, from 0 $\mathrm{W} / \mathrm{m}^{2}$ to a heavy one with a load equal to $22 \mathrm{~W} / \mathrm{m}^{2}$ ).

The impact of external gains/conditions has been tested through the parametric analysis of: the solar irradiation (increased and decreased in steps up to $\pm 20 \%$ ); the outdoor air temperature increase (from $+0.5{ }^{\circ} \mathrm{C}$ to +3.5 ${ }^{\circ} \mathrm{C}$ ); the shading context (from unshaded building to heavily shaded building); and the solar gains (by changing the glazing's g-value from $-20 \%$ to $+20 \%$ ). These boundaries are defined to evaluate likely weather variations and wrong predictions, which might significantly affect the building behaviour, and the passive systems of intrinsic control implemented. Variations are applied to the weather data file (.epw) for the two locations retrieved from the Weather Data files page of EnergyPlus (EnergryPlus, 2019).
The impact of building materials properties has been studied through the parametric analysis of: the thermal transmittance of the windows (by changing the U-value of the glazing in steps from $-20 \%$ to $+20 \%$ ); the thermal inertia of all the opaque elements (by changing the specific heat capacity in steps from $-20 \%$ to $+20 \%$ ); and the thermal resistance of all the opaque elements (by changing the thermal conductivity of the materials in steps from $-20 \%$ to $+20 \%$ ).

Finally, the impact of the PCM properties has been studied through the parametric analysis of: the energy storage potential of the PCM (by changing the enthalpy of fusion in steps from $-20 \%$ to $+20 \%$ ); the transition phase temperature (by changing the nominal temperature of fusion in steps from $-2{ }^{\circ} \mathrm{C}$ to $+2{ }^{\circ} \mathrm{C}$ ); and the hysteresis features of the PCM (by including a nohysteresis case and four different hysteresis values).

The total count of simulation adds up to 81 cases for each climate, run in EnergyPlus 8.9.

\section{Results}

\section{Overview and parameter hierarchy}

In Figure 4 the results of the entire simulation study are summarised for an immediate reading, regardless of the case analysed. The aim is to assess at glance the magnitude of all the different parameters. It can be easily understood that variations in the internal gains are by far those that lead to larger discrepancies between expected (reference case scenarios) and the obtained energy use.

In Trondheim, an overestimation of the internal gains in the design phase (and in particular of the equipment load) can lead to an increased energy use for heating in the order of 4-5 times the original value. On the contrary, a variation in any of the parameters of all the other categories can potentially lead only to an energy use for heating less than twice the reference one. A variation in the internal gains (either lighting load or equipment load) or in the solar gains can increase the cooling energy use, in Trondheim, up to more than $2 \mathrm{kWh} / \mathrm{m}^{2}$ (with the reference case having nearly $0 \mathrm{kWh} / \mathrm{m}^{2}$ cooling energy use).

A similar trend, but with different magnitude for heating and cooling energy use, can be seen in Barcelona. Underestimation of internal gain (assessed in the simulation as lighting load and equipment load), as well as of solar gains, can lead to nearly triple the energy use for cooling. When it comes to energy use for heating, the case study seems to be very insensitive to the different variations in the parameters.

The only exception is the underestimation of the equipment load, which can lead to an increase in the heating energy use of little less than $2 \mathrm{kWh} / \mathrm{m}^{2}$ (while the reference case showS nearly $0 \mathrm{kWh} / \mathrm{m}^{2}$ for heating).

In the next sections, a more detailed analysis is presented for each of the four main categories (internal gains, external gains/conditions, material properties, and PCM properties) to highlight how the performance of the cases with PCM-enhanced solutions is more stable than the correspondent one of the reference case (no PCM). 
PARANERRC ANAIIZE

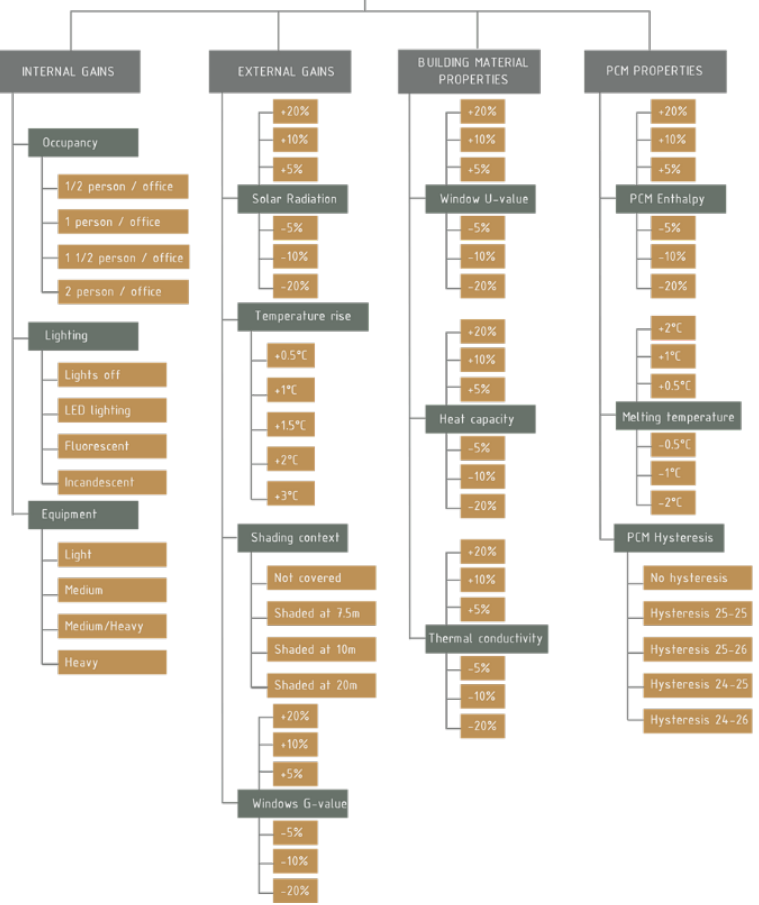

Figure 3: Overview of categories and parameters, and values considered in the study.

\section{Detailed analyses and robustness of PCM-enhanced cases: internal gains}

Internal gains is the category that leads to the largest variation in the energy use, and thus the category where it is best shown how the adoption of PCM-enhanced technologies is reflected in the deviation from the planned performance.

In Figure 5, the results of the simulations for different occupancy densities are shown for the heating and cooling energy use in a Nordic climate. It is possible to see that the trends (when density increases, a decrease of the heating energy use and an increase of the cooling energy use is observed) are meaningful, and that the solution with PCM-enhanced constructions (continuous line) always shows a better performance, and lower increase in energy use when compared to the solution without PCM-based systems (dashed lines).

In the worst-case scenario, (doubling the density of occupants), the cooling energy use without PCM reaches a value that is twice as that for the case with PCM.

Figure 6 shows the same analysis for the Mediterranean climate. This case represents the only one, in the entire spectrum of configurations analysed, where the adoption of PCM-based constructions can lead to a worst performance than that of a building based on conventional construction elements, when the boundary conditions differ from the ones used in the design phase. This behaviour is seen in the case of the heating energy use; however when the office is simulated as unoccupied (no internal gain due to the people) - and therefore a situation unlikely to occur, or not really of real interest. In this situation, the missing heat gains due to occupants prevent the activation of the PCM integrated in the building fabrics, and therefore lead to a worst performance compared to the conventional building without PCM-based components.

However, already when the occupancy is equal to half of that considered in the design phase, the energy use for heating in the case of the building with PCM-enhanced systems is lower (and more stable) than that of the case without PCM. Only with very high density (double than that of the reference case scenario), the energy use with and without PCM is almost the same.

If the occupancy density increased even further, the performance of the two systems would probably continue to be equal, since with very high occupancy the advantages given by the PCM are no longer there.

For the sake of brevity and space, not all the cases analysed can be shown in the paper. The impact of both different lighting and equipment load is very similar in shape and differ only in magnitude (being the equipment load the one with the highest influence on the heating and cooling). Just one case is shown herewith for each climate: the impact of different lighting load for the Nordic climate (Figure 7) and the impact of the equipment load for the Mediterranean climate (Figure 8).
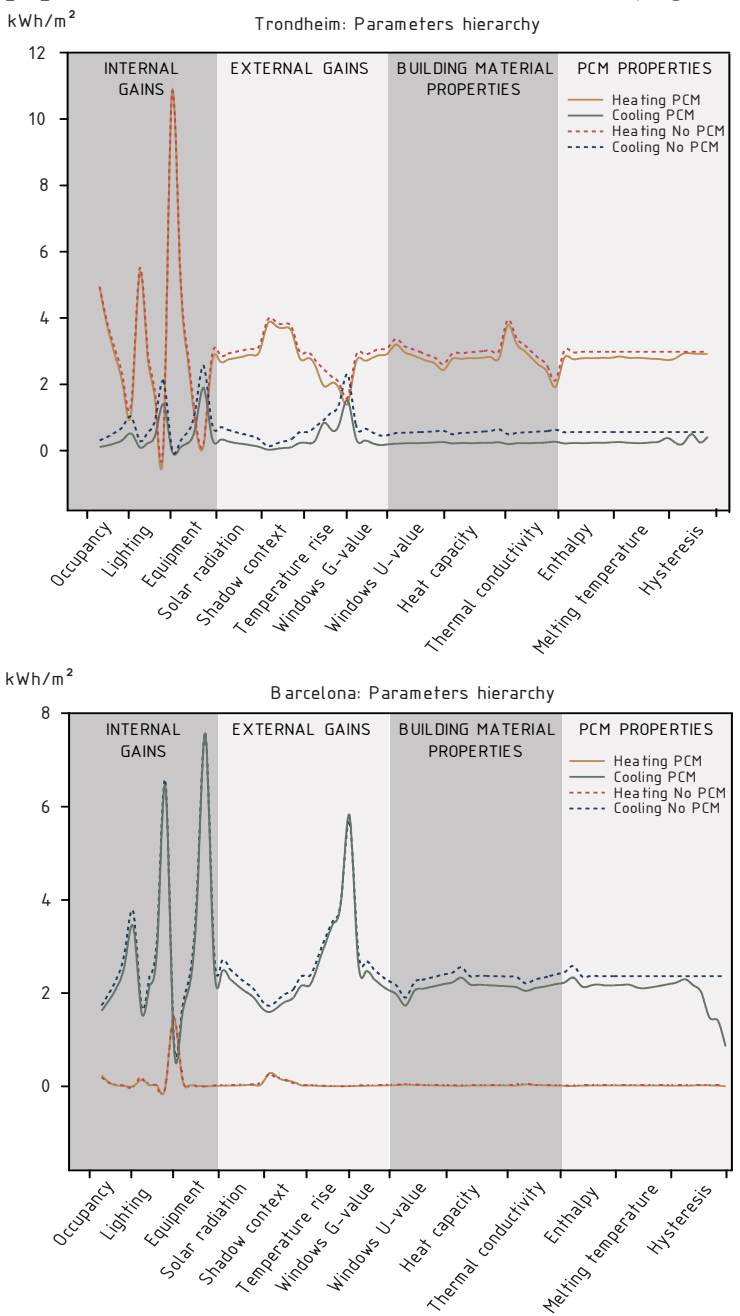

Figure 4: Overview of the impact of the different parameters, for the case with and without PCM, in Trondheim (top) and Barcelona (Bottom). 

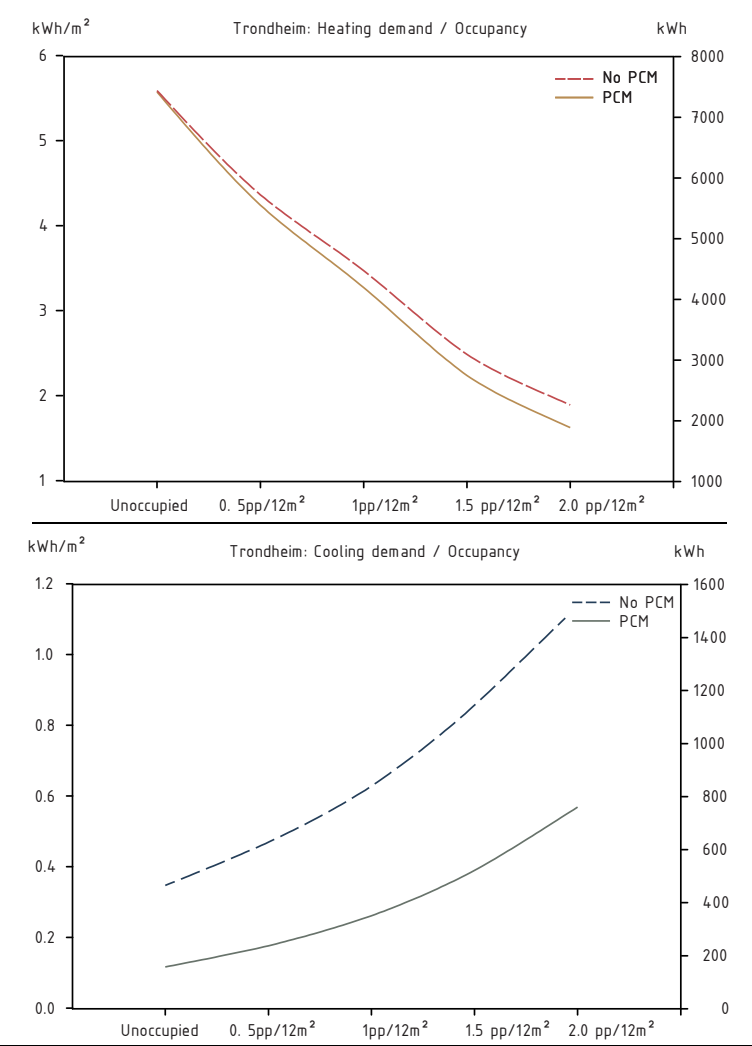

Figure 5: Impact of the different occupancy density on the heating (top) and cooling (bottom) energy use in the Nordic climate (Trondheim).

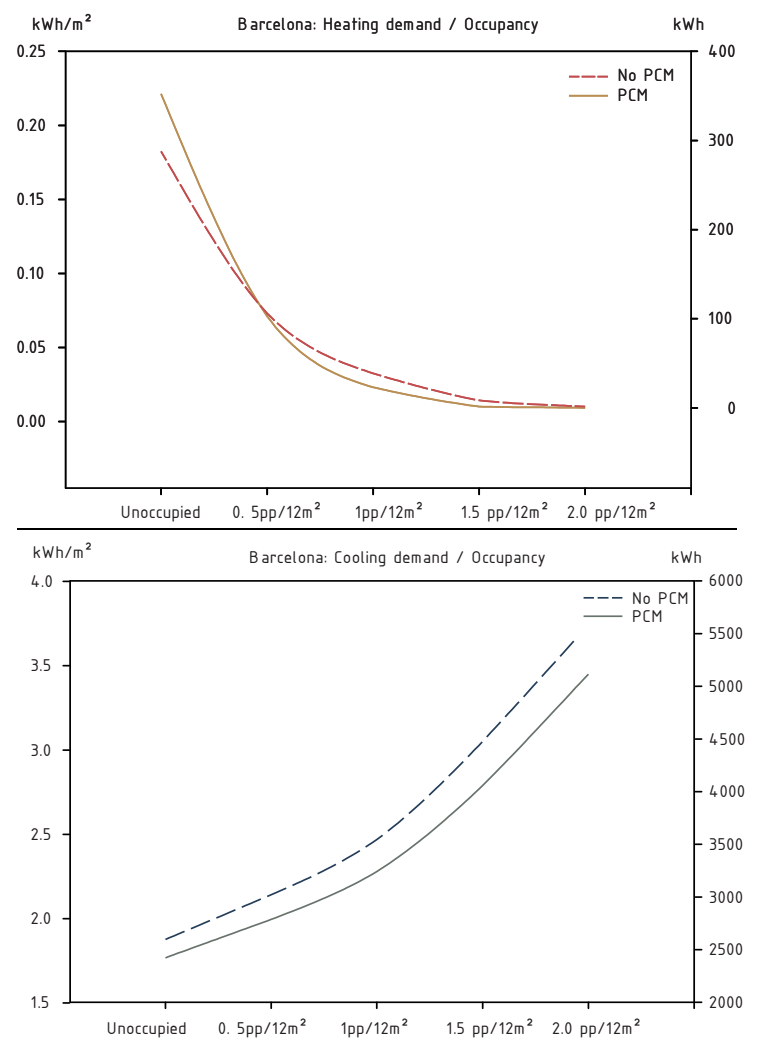

Figure 6: Impact of the different occupancy density on the heating (top) and cooling (bottom) energy use in the Mediterranean climate (Barcelona).

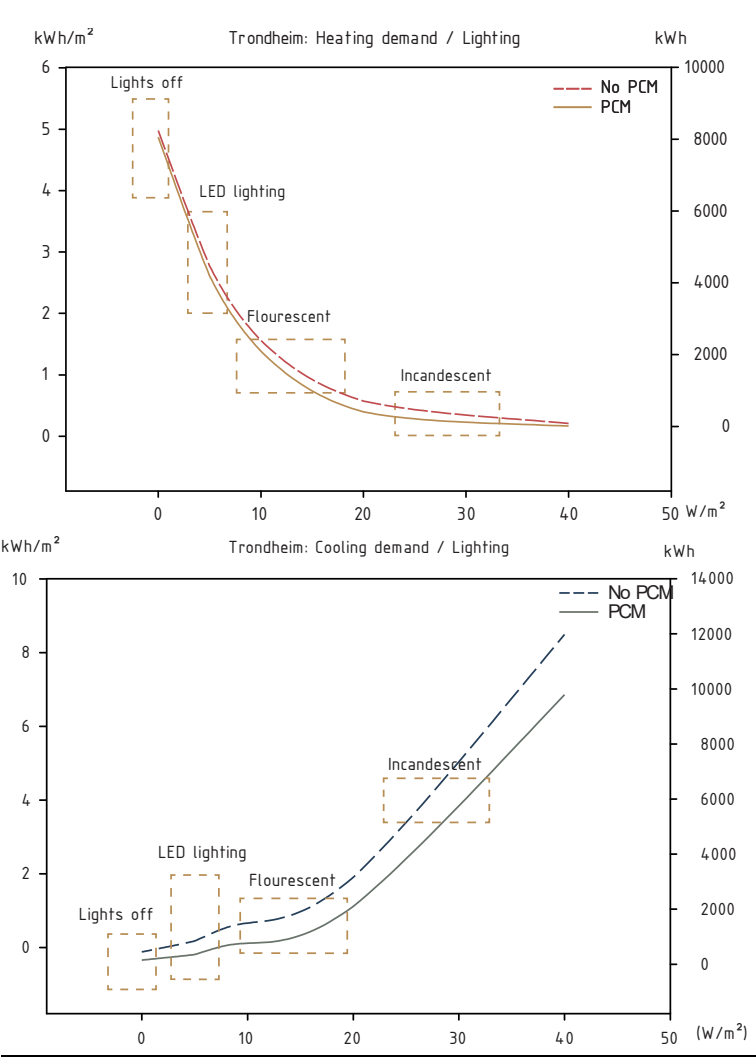

Figure 7: Impact of the different lighting load on the heating (top) and cooling (bottom) energy use in the Nordic climate (Trondheim).

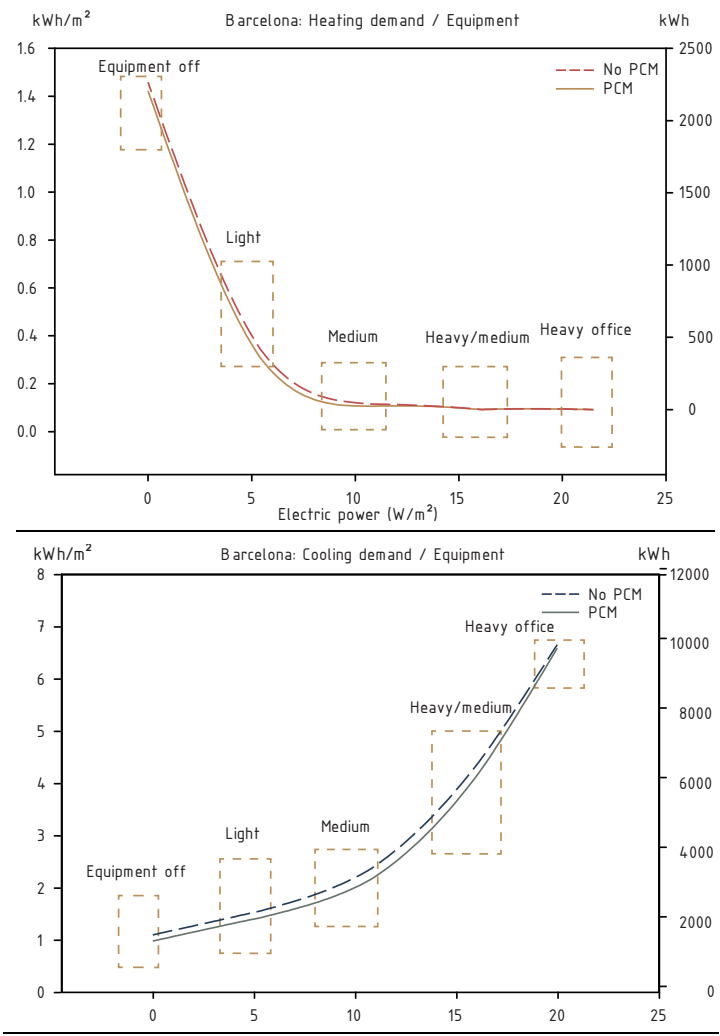

Figure 8: Impact of the different equipment load on the heating (top) and cooling (bottom) energy use in the Mediterranean climate (Barcelona). 
For all the cases, the simulation results return reasonable trends (higher internal gains lead to lower heating energy use and higher cooling energy use), and the PCM-based building always shows a more robust behaviour (i.e. smaller variation) than the reference without PCM.

The change in the performance is not always linear, even if the variation of the load value is done in constant steps. The impact on the heating energy use (increase) is larger when the variation of the parameters (lighting or equipment load) is in the lower range (under the design value) while the impact on the cooling energy use is larger when the variation of the parameters is in the higher range (above the design value).

In summary, the analysis of the impact of internal gain shows that the PCM-enhanced systems are not "badly" sensitive (i.e. they do not respond with a higher increase in energy use than the case without PCM) when a different internal gain occurs. Therefore, the use of PCM presents a low-risk when it comes to uncertainty in parameters during the design phase, as well as, to changes in the operation of the building.

\section{Detailed analyses and robustness of PCM-enhanced cases: external gains}

The analysis of the impact of the heat gains from the outside comprises three possible variations of boundary conditions, but only the two most relevant ones are presented here: the shadow context (Figure 9), and the solar gain through the windows (Figure 10).

This last variation, obtained in the simulation through the change of the g-value of the windows, can represent different changes in the operation or boundary conditions (e.g. unplanned use of shading devices, difference in the impinging solar radiation between the weather data file and the real weather conditions).

In terms of intensity, the shadow context has a larger impact on the heating energy use (in the Nordic climate) than on the cooling energy use (in the Mediterranean climate) when compared to the variation of the g-value of the window. Both variations naturally lead to an increase of the heating energy use when the incoming solar gain is reduced, and in an increase of the cooling energy use when the solar gain increases (either because of a higher g-value or because of an unshaded building).

Regardless of the parameter analysed, the building equipped with PCM-based constructions is always performing better, and the change in the performance is equal to that of the building without PCM (in Figure 9 and 9 the profiles of the energy use for both the solution with and without PCM are parallel). This shows that there is not a worsening of the performance of the building equipped with PMC-enhanced components when the boundary conditions differ from the one used to determine the optimal PCM's features, highlighting once that this solution is robust against unexpected changes during the building operation.

The selected reference case (nominal melting temperature of $25^{\circ} \mathrm{C}$ ) is, in fact, the one that globally (heating plus cooling) leads to the best performance.
The results of the dependence of the energy use on the two other PCM's properties investigated are not here reported for the sake of brevity, but the variation between the original performance and the worst-case scenario is always below $3 \%$.

\section{Detailed analyses and robustness of PCM-enhanced cases: building materials properties}

The sensitivity analysis of the building materials properties shows a very small dependence of the building energy performance on the thermal transmittance of the windows and on the specific heat capacity of the building materials. This is probably because the reference (optimised) building is characterised by a very high energy performance, and the variation range explored in the analysis is probably too small to have an impact on the overall behaviour.

The parameter that has the largest impact on the performance is the thermal resistance of the envelope, and such an influence is, as expected, larger on the heating energy use than on the cooling energy use (Figure 11). Once more, implementing or not PCMbased systems in the building is reflected in an overall lower energy use, but not on the relative variation between the two configurations. The case with the PCM always shows a better performance, and any change in the thermal resistance of the envelope has the same intensity in the cases with and without the PCM.

\section{Detailed analyses and robustness of PCM-enhanced cases: PCM properties}

The last category analysed in this study deals with the PCM's properties. For this reason, the results only refer to the case of the building equipped with the PCMenhanced constructions. The scope is therefore not to verify if a change in the boundary conditions can lead to a worse performance than in a building without PCM, but to check that a change in the boundary conditions does not reflect in a sensible worse performance.

As an example for this category, the change in the performance due to a different nominal melting temperature of the PCM is shown in Figure 12. The results show that a shift in the nominal melting temperature range lead to an increase or decrease in the range of less than $3 \%$ for the heating energy use (in the Nordic climate) and the cooling energy use (in the Mediterranean climate).

From the results it may seems that the selected reference case (nominal melting temperature of $25^{\circ} \mathrm{C}$ ) is not the best possible one, since the energy performance in both heating (for the Nordic climate) and cooling (for the Mediterranean climate) can be improved. However, the results shown in Figure 12 are only partial, as the cooling energy use in Trondheim and the heating energy use in Barcelona are not shown.

\section{Discussion and limitations of the study}

The general results of the study have highlighted how a PCM-based is foreseen to perform better than an identical building not equipped with such a technology. 


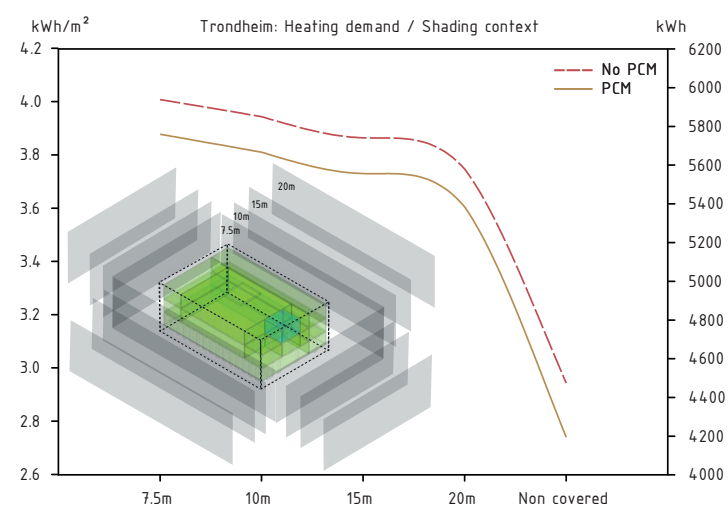

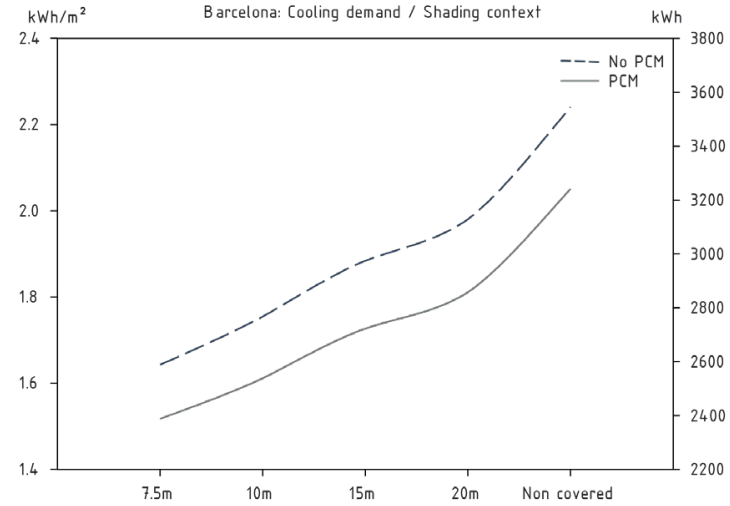

Figure 9: Impact of the shadow context on the heating (top) energy use in the Nordic climate and the cooling (bottom) energy use in the Mediterranean climate.
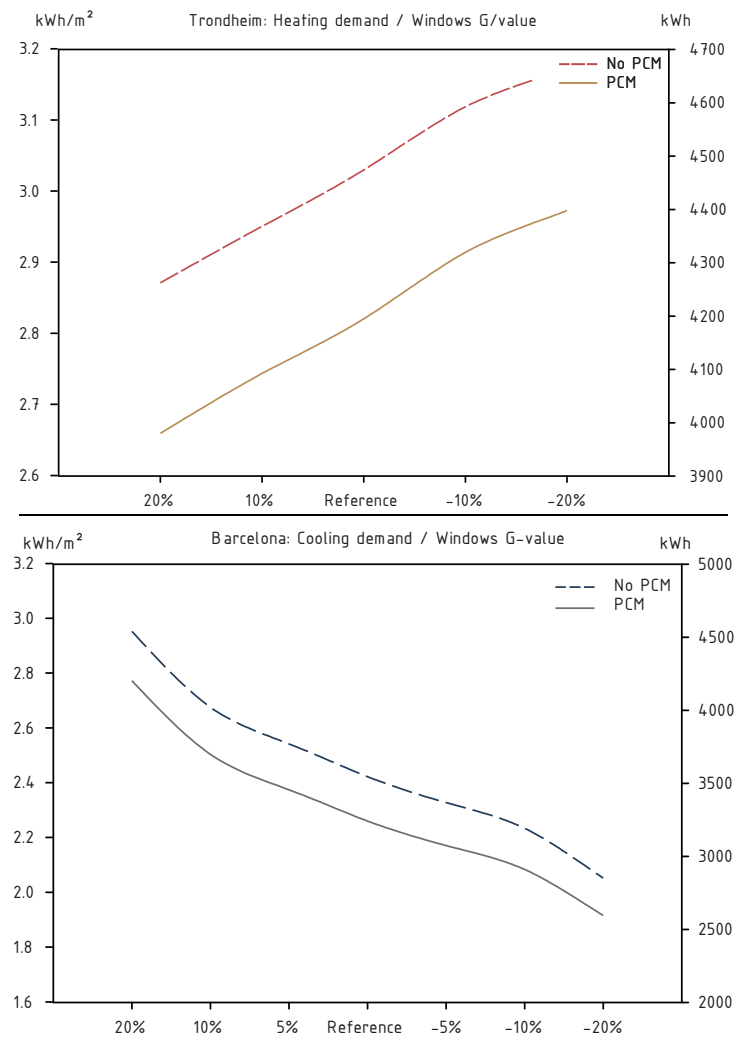

Figure 10: Impact of the solar gain on the heating (top) energy use in the Nordic climate and the cooling (bottom) energy use in the Mediterranean climate.
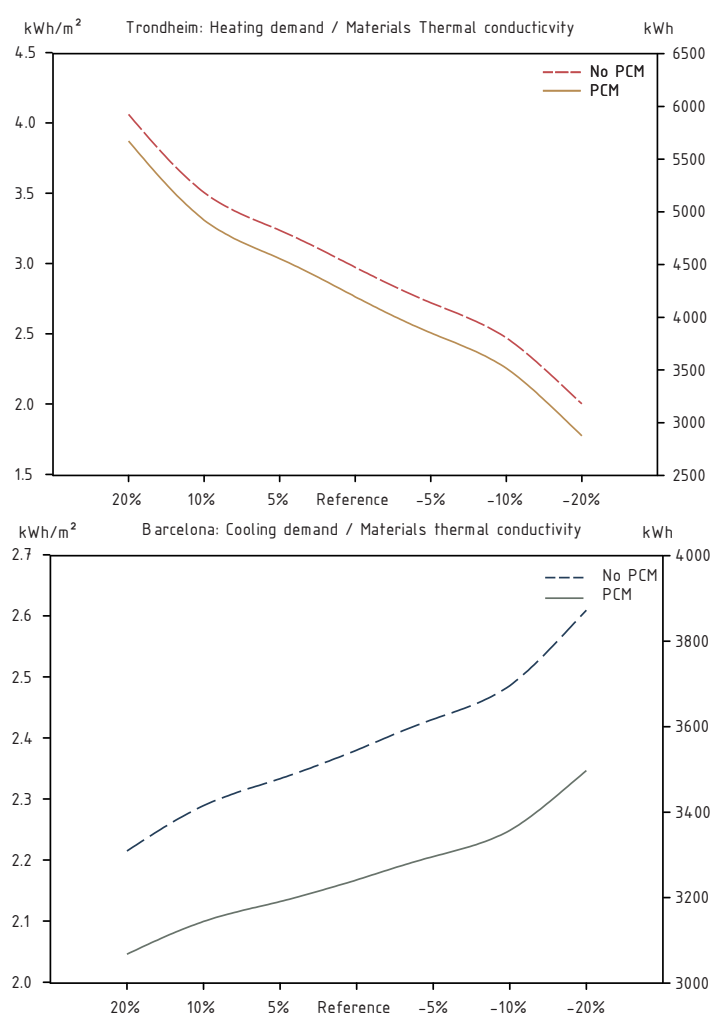

Figure 11: Impact of the thermal conductivity on the heating (top) energy use in Trondheim and the cooling (bottom) energy use in Barcelona.
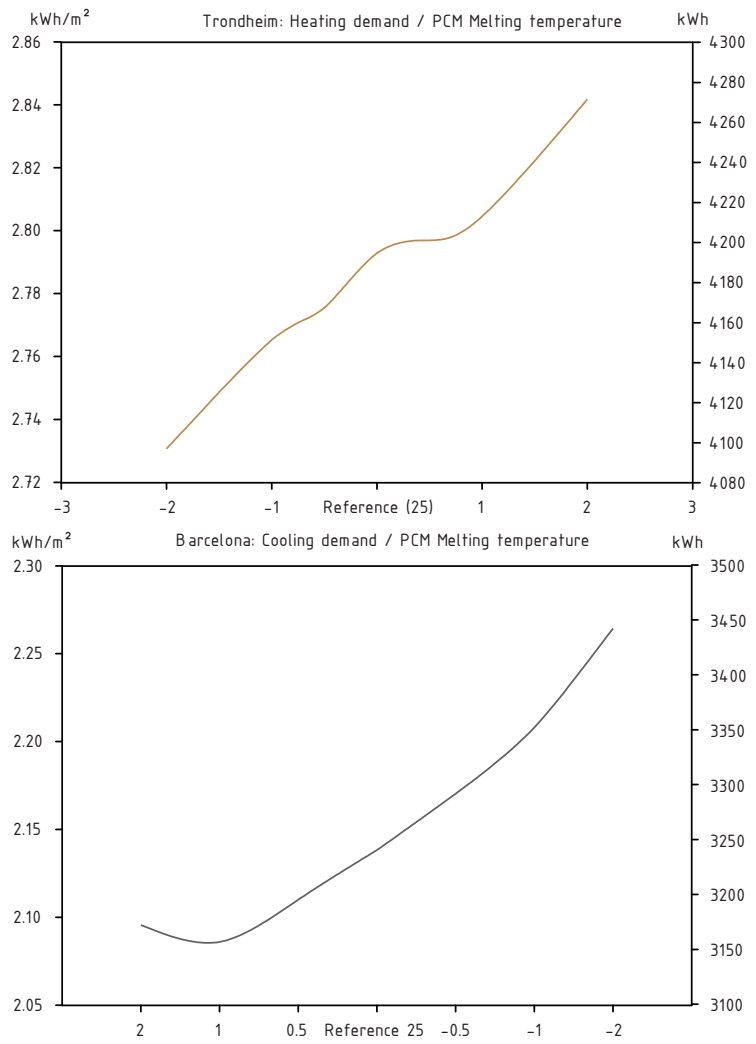

Figure 12: Impact of the PCM's nominal melting temperature on the heating (top) energy use in Trondheim and the cooling (bottom) energy use in Barcelona. 
It should be mentioned that in the analysis carried out a large amount of the building's surfaces exposed to indoor air (the entire envelope, interior partition walls, and ceiling) has been covered with PCM (installed behind a gypsum board). This analysis is therefore a theoretical situation, where the consequences of using PCM are assessed under extreme conditions that are not probably met in a conventional design situation.

However, such an approach is coherent with the scope of this paper, which is to understand the robustness of PCM-based systems under operation conditions that differ from the originally planned ones. With this aim in mind, the simulation of a large amount of surfaces covered with PCM represents the worst-case scenario, where energy use is very small and any potential change in the energy use due to a possible non-robustness behaviour of PCM is be amplified.

The selection of parameters to be tested has left unexplored some domains that might be relevant too for example, a failure or misuse of the night-cooling or ventilation strategies, which is known to be a crucial element to support the performance of the PCM layers (Álvarez et al. 2013). It is therefore possible that a change in some parameters not considered in this study might lead to a worse performance for the PCM case than for the reference, PCM-free building, and the conclusion about the robustness of the PCM-based system is therefore only valid for the analysed variation in boundary conditions.

One last point of discussion concerns the ability of EnergyPlus to simulate with good accuracy PCM-based systems. Validation of the code has been carried out by comparison with experiments (Tabares-Velasco et al. 2012), however a more recent investigation has shown how, when the PCM hysteresis is modelled, and the melting/re-solidification process is not complete, relevant discrepancies between simulated and experimental values are seen (Goia et al. 2018). However, this phenomenon is particularly relevant for PCM characterised by high thermal hysteresis, which is usually less evident in paraffin-based PCM (such as the material chosen for this study).

\section{Conclusion}

The results of the robustness (parametric) analysis demonstrate that PCM-enhanced building components are robust solutions to assure a high-energy performance. Even if boundary conditions differ from that originally used in the design phase, the adoption of PCM-based constructions does not lead to an increase in the risk of unwanted effects.

Different categories of variations in boundary conditions have been tested and, for almost all the cases, the PCMbased office building presents not only a better performance, if compared to that of an equivalent building without PCM, but a greater insensitivity (i.e. robustness) towards variations in the operations. Among all the categories analysed, a change in the internal gain (and in particular either in the lighting load or in the equipment load) is the one with a greater impact on the energy performance, while other categories (such as outdoor boundary conditions, material properties, and PCM properties) only show a limited impact.

\section{Acknowledgement}

The authors acknowledge the networking opportunities given by the Cost Action TU1403 "Adaptive Facades Network", through which this research activity has been initiated. Dr. Albert Castell would like to thank the Catalan Government for the project grant (2017 SGR $659)$ given to his research group.

\section{References}

Álvarez, S., Cabeza, L.F., Ruiz-Pardo, A., Castell, A., Tenorio, J.A. (2013). Building integration of PCM for natural cooling of buildings, Applied Energy $109(C)$, 514-522.

ASHRAE (2017). Handbook-Fundamentals

Castell, A., Medrano, M., Goia, F. (2018). Modelling envelope components integrating Phase Change Materials (PCMs) with whole-building energy simulation tools: a state of the art. Journal of Facade Design and Engineering 6(3), 132-148.

EnergyPlus weather data file webpage (accessed January 2019): https://energyplus.net/weather

Goia, F., Chaudhary, G., Fantucci, S. (2018) Modelling and experimental validation of an algorithm for simulation of hysteresis effects in phase change materials for building components. Energy and Buildings 174, 54-67.

Kośny, J. (2015). PCM-Enhanced Building Components. Springer International Publishing, Cham.

International Organisation for Standardisation (2012). Indoor environmental input parameters for design and assessment of energy performance of buildings addressing indoor air quality, thermal environment, lighting and acoustics (ISO 12521).

Pomianowski, M., Heiselberg, P., Zhang, Y. (2013) Review of thermal energy storage technologies based on PCM application in buildings. Energy and Buildings 67, 56-69.

Rubitherm RT25HT datasheet (accessed January 2019): https://www.rubitherm.eu/media/products/datasheets/ Techdata -RT25HC EN 05092018.PDF

Tabares-Velasco, P.C., Christiansen, C., Bianchi, M. (2012). Verification and Validation of EnergyPlus Conduction Finite Difference and Phase Change Material Models for Opaque Wall Assemblies. Building and Environment 54, 1-55.

Vigna, I., Bianco, L., Goia, F., Serra, V. (2018). Phase change materials in transparent building envelopes: a strengths, weakness, opportunities and threats (SWOT) analysis. Energies 11, Article number 111. 